\section{Satisfaction with facial laceration repair by provider specialty in the emergency department}

\author{
Sang-Jae Lee, Young-Duck Cho, Sung-Jun Park, Jung-Youn Kim, \\ Young-Hoon Yoon, Sung-Hyuk Choi
}

Department of Emergency Medicine, Korea University College of Medicine, Seoul, Korea

Objective We compared patient satisfaction with scarring after facial laceration repair in the emergency department (ED) based on the specialty of the provider.

Methods Patients with facial lacerations admitted to the ED from 2009 to 2013 were divided into two groups. One group of patients underwent repair by an emergency physician (EP) and the other by a plastic surgeon (PS). From August 2014 to September 2014, we randomly selected $10 \%$ of all patients and assessed their degree of satisfaction with scarring over the phone using a 5-point Likert scale.

Results The male to female ratio was 2.81 in the EP group and 2.05 in PS $(P<0.001)$. The proportion of those aged 0 to 9 years among all the patients was higher in the PS group than in the EP group (50.8\% vs. $30.1 \%$, respectively, $P<0.001)$. The duration of $E D$ stay was $107.8 \pm 84.6$ minutes in the EP group and $225.9 \pm 161.8$ minutes in the PS group $(\mathrm{P}<0.001)$. Among these patients, 228 responded to a telephone survey. A poor satisfaction score of 1 to 2 was more common in female or young patients who underwent repair by an EP $(P<0.05)$. However, the overall satisfaction among all respondents did not differ between the two groups.

Conclusion Although female patients and the guardians of young children who underwent simple facial laceration repair by a PS were more satisfied than those treated by an EP, the satisfaction of the entire group of patients did not differ according to the treatment provider.

Keywords Facial laceration; Personal satisfaction; Emergency service, hospital

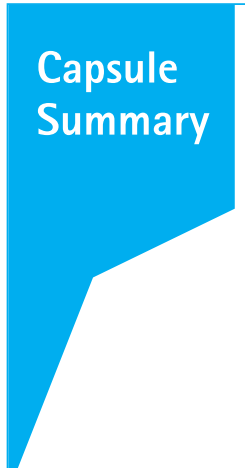

What is already known

With the increased number of emergency department physicians, more facial lacerations might be repaired by emergency physicians than be-fore.

What is new in the current study

Although female and young patients with simple facial lacerations repaired by plastic surgeon were more satisfied than those repaired by emergency physician, the overall satisfaction in the entire group of patients did not differ depending on the physician specialty.
elSSN: 2383-4625

Received: 11 May 2015

Revised: 18 May 2015

Accepted: 19 May 2015

Correspondence to: Young-Hoon Yoon Department of Emergency Medicine, Korea University Guro Hospital, 148 Gurodong-ro, Guro-gu, Seoul 152-703, Korea

E-mail:yyh71346@naver.com

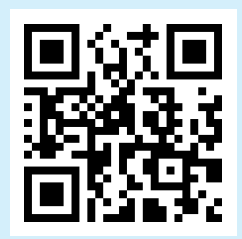

How to cite this article:

Lee SJ, Cho YD, Park SJ, Kim JY, Yoon YH, Choi SH. Satisfaction with facial laceration repair by provider specialty in the emergency department. Clin Exp Emerg Med 2015;2(3):179-183.

This is an Open Access article distributed under the terms of the Creative Commons Attribution Non-Commercial License (http:// creativecommons.org/licenses/by-nc/3.0/). 


\section{INTRODUCTION}

Facial lacerations are a common reason for visiting an emergency department (ED), and the assessment and management of facial lacerations account for a significant proportion of ED workload. The incidence of facial wounds is between $4 \%$ and $7 \%$ of all accident and emergency visits. ${ }^{12}$ Most wounds that occur on the face will leave a scar regardless of how they are repaired. The principal goal in the management of facial lacerations is to close the wound and avoid infection. Another important objective in the management of facial lacerations is to reduce scarring in order to prevent long-term cosmetic and psychological sequelae. The cosmetic outcome of the scar after a repair is of particular importance to the patient or guardian. ${ }^{3-5} \mathrm{~A}$ considerable number of adult patients and parents or guardians of pediatric patients prefer that their lacerations be repaired by a specialist such as a plastic surgeon (PS) to minimize scarring and promote better cosmetic outcomes.

In this study, we analyzed patients with facial lacerations to evaluate their satisfaction with facial scarring after being treated in the ED .

\section{METHODS}

This study involved all patients with facial lacerations visiting the Korea University Guro Hospital Emergency Department from 2009 to 2013. The institutional review board of our hospital approved this study. Our ED has approximately 60,000 visits per year and $30 \%$ to $35 \%$ of total visits are trauma patients. When a patient with facial lacerations visits the ED, all simple wounds are sutured by an emergency physician (EP) in the hospital's ED. If a patient or caregiver requests repair by a PS or a patient with complex lacerations requires specialty consultation, the EP calls the PS resident on duty and the patient receives repair by the PS. Following the policy of our hospital, we did not offer patients in this study an option to choose which department would provide them surgical treatment. Most of the EPs and PSs performing the procedure were first-year residents.

In this study, all patients who underwent repair for simple facial laceration in the ED were included. Patients with multiple injuries as well as those who were admitted, transferred, and received a workup other than simple radiography were excluded.

The patients with facial laceration were then divided into 2 groups. One group consisted of patients who had undergone repair by an EP, and the other group included patients who had received treatment from a PS. The collected data were age, gender, wound site, duration of stay in the ED, and the department that provided the repair.
Among all of the patients included, we randomly selected 10\% of them following a previously described survey sampling method. ${ }^{6}$ The medical records of the selected patients were reviewed by the investigator. The following patients were excluded: those with puncture wounds (less than $2 \mathrm{~mm}$ ), small lacerations (less than $2 \mathrm{~cm}$ ), infected wounds, wounds with a skin defect, or wounds involving the vermillion; those using an immunosuppressive agent; and those with immune deficiency, an autoimmune disorder, or diabetes. Patients with lacerations that had occurred more than 8 hours before the ED visit and those with complex lacerations who required more than simple repair were also excluded. In the end, those who remained in the 2 groups had lacerations with approximately the same degree of severity. From August 2014 to September 2014, we assessed the degree of patients' or their guardians' satisfaction of residual scarring by phone using a 5-point Likert scale ( $1=$ very unsatisfied, $2=$ not satisfied, $3=$ neutral, $4=$ satisfied, $5=$ very satisfied).

\section{Statistical analysis}

Continuous variables are expressed as the mean \pm standard deviation. The independent Student's t-test was used for continuous variables with symmetric distribution. The chi-squared test was used to verify the differences among the 5 different Likert scores. A 2-tailed $P<0.05$ was considered to be statistically significant. All statistical analyses were performed using IBM SPSS Statistics ver. 19.0 (IBM Corp., Armonk, NY, USA).

\section{RESULTS}

The number of patients with facial lacerations was 14,154. After applying the exclusion criteria (multiple injury, admission, transfer, and receiving a workup beyond simple radiography), 3,552 patients remained. Of all patients 1,003 patients underwent repair by a PS and 2,547 patients underwent repair by an EP. The mean age was $26.7 \pm 21.5$ years in patients who underwent repair by an EP and $18.7 \pm 20.0$ in patients who were treated by a PS $(P<0.001)$. Wound sites were categorized into forehead, periocular, cheek and temporal, and chin area. The proportions of each wound site did not differ according to the specialty of treatment. The duration of ED stay was $107.8 \pm 84.6$ minutes in patients who underwent repair by an EP and 225.9 \pm 161.8 minutes in patients who underwent repair by a PS. The male to female ratio was 2.81 in patients who underwent repair by an EP and 2.05 in patients who underwent repair by a PS $(P<0.001)$ (Table 1$)$. The proportion of those aged 0 to 9 years among all of the patients was higher in patients who underwent repair by a PS than by an EP (50.8\% vs. 30.1\%, $\mathrm{P}<0.001$ ) (Fig. 1). 
From these 3,552 patients, 355 randomly chosen individuals were contacted via a telephone survey and 228 patients or patients' guardians (64.2\%) responded. Among those who responded to the telephone survey, 167 patients had undergone repair by an ED and 61 patients by a PS. Among the patients who had undergone repair by an EP, 5.4\% of patients had the lowest satisfaction score of 1, 18.0\% scored 2, $27.5 \%$ scored 3, 37.1\% scored 4 , and $12.0 \%$ had the highest score of 5 . Among those who had undergone repair by a PS, 3.3\% scored 1, 23.0\% scored 2, 29.5\% scored 3, 27.9\% scored 4, and 16.4\% scored 5 (Fig. 2). Statistical differences were not observed between the two groups. As the proportion of females and those aged 0 to 9 years were higher in patients who underwent repair by a PS than in those repaired by an EP, we performed a subanalysis of each of these two demographic groups of patients. Among those in the youngest age group of 0 to 9 years who underwent repair by an EP, 27.8\% of guardians scored their satisfaction at the lowest levels of 1 or 2 , $38.9 \%$ reported a score of 3, and 33.3\% reported high satisfaction scores. For the youngest patients who underwent treatment

Table 1. General characteristics of included patients

\begin{tabular}{lccc}
\hline & $\begin{array}{c}\text { Patients sutured by EP Patients sutured by PS } \\
(n=2,547)\end{array}$ & P-value \\
& $26.7 \pm 21.5$ & $18.7 \pm 20.0$ & $<0.001$ \\
\hline Age $(y r)$ & $2.81: 1$ & $2.05: 1$ & $<0.001$ \\
M:F ratio & & & \\
Wound site & $321(12.6)$ & $116(11.6)$ & 0.438 \\
$\quad$ Forehead & $1,636(64.2)$ & $672(67.0)$ & 0.115 \\
$\quad$ Periocular region & $456(17.9)$ & $168(16.7)$ & 0.451 \\
Cheek & $134(5.3)$ & $47(4.7)$ & 0.559 \\
$\quad$ Chin & $107.8 \pm 84.6$ & $225.9 \pm 161.8$ & $<0.001$ \\
\hline
\end{tabular}

Values are presented as mean \pm standard deviation or number (\%) unless otherwise indicated.

$E P$, emergency physician; PS, plastic surgeon; ED, emergency department.

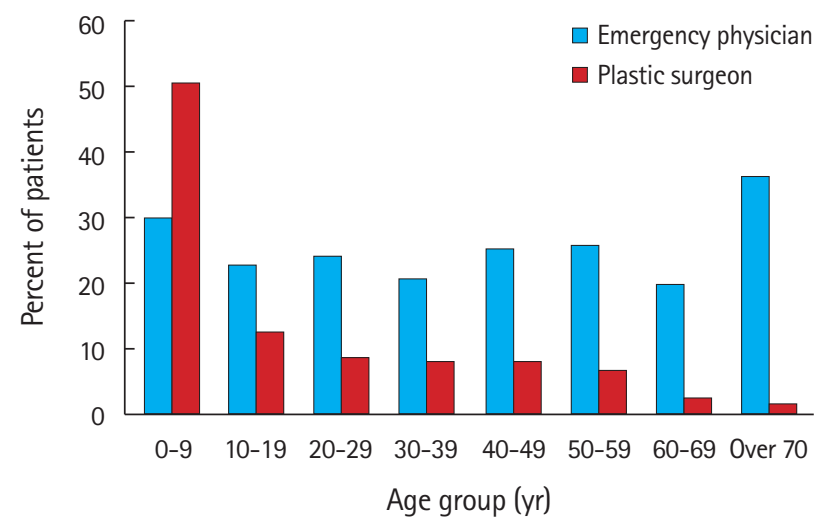

Fig. 1. The proportion of patients receiving surgical treatment by specialty in each age group. All P-values for differences in each age group was less than 0.05 . by a PS, $20 \%$ of guardians scored 1 or $2,24.0 \%$ scored 3 , and $56.0 \%$ scored 4 or 5 (Fig. 3). Among the female patients who responded to the telephone survey, more patients who underwent repair by an EP than a PS scored their satisfaction at 1 or $2(\mathrm{P}<$ 0.05) (Fig. 4).

\section{DISCUSSION}

To our knowledge, this study is the first to compare patient satisfaction between facial laceration repair providers. Lacerations are one of the most common reasons for visiting the ED.? Although most patients with lacerations do not want a noticeable scar anywhere on the body, scarring on the face is the most concerning. Tebble et al. ${ }^{8}$ reported that considerable and persistent psychological changes may develop due to even minor maxillofacial injuries and that the size of the scar has a psychological impact

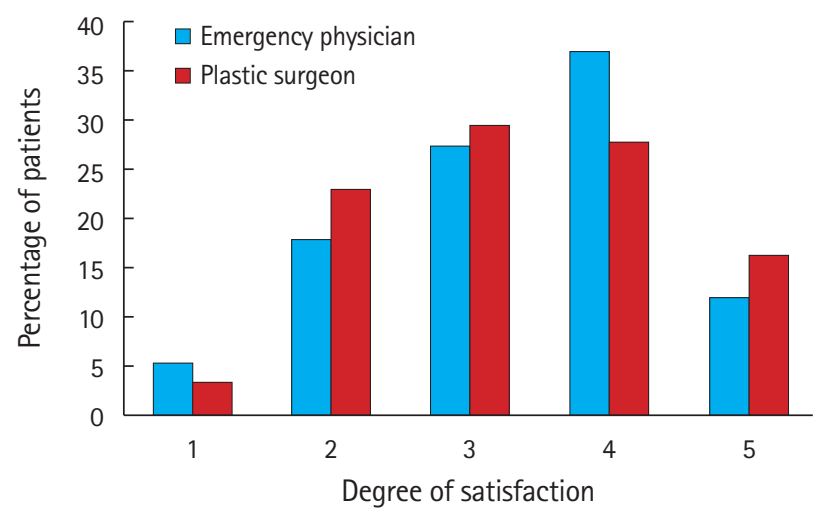

Fig. 2. The degree of patients' or guardians' satisfaction with scarring using a 5-point Likert scale in the entire study population ( $1=$ very unsatisfied, $2=$ not satisfied, $3=$ neutral, $4=$ satisfied, $5=$ =very satisfied).

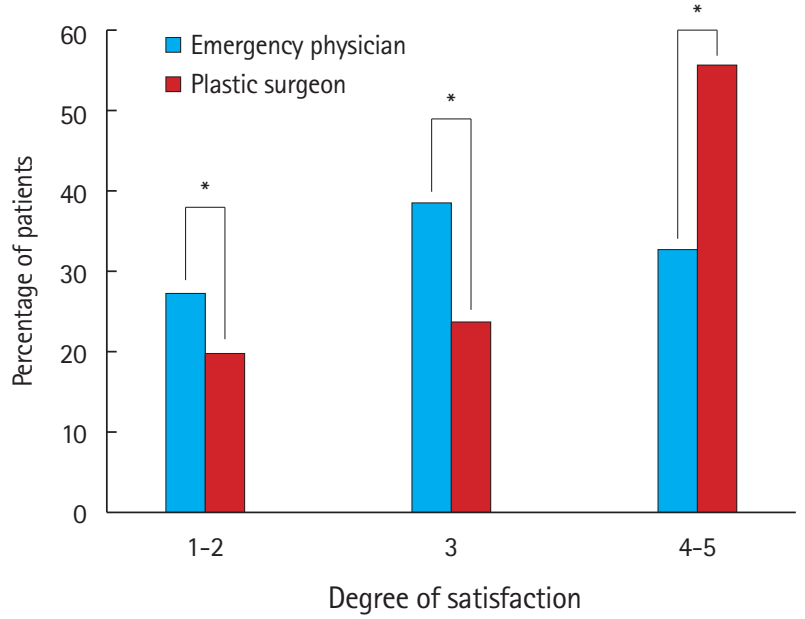

Fig. 3. The degree of guardians' satisfaction with scarring using a 5 -point Likert scale in patients under 10 years of age ( $1=$ very unsatisfied, $2=$ not satisfied, $3=$ neutral, $4=$ satisfied, $5=$ very satisfied). ${ }^{*} \mathrm{P}<0.05$. 


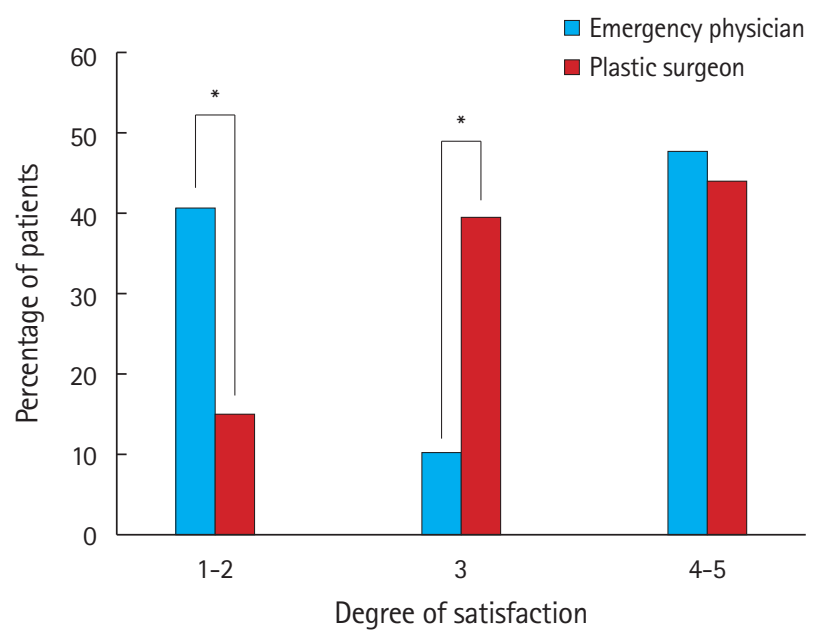

Fig. 4. The degree of patients' satisfaction with scarring using the 5 -point Likert scale in female patients ( $1=$ very unsatisfied, $2=$ not satisfied, $3=$ neutral, $4=$ satisfied, $5=$ very satisfied). ${ }^{*} P<0.05$.

on patients.

However, no standard guideline or protocol relating to the management of facial lacerations in the ED has been established. Many different guidelines for when to refer to a specialist may exist according to individual hospital policies. Kim et al. ${ }^{9}$ reported that only $10 \%$ of patients visiting an ED for facial laceration received primary repair by emergency medicine physicians in their hospital. Eighty percent of all patients with facial laceration received repair in the ED by a PS. In 2001, when the aforementioned report by Kim et al. ${ }^{9}$ was made, only 219 ED physicians were practicing in Korea. The number of ED physicians had increased to 1,175 by $2013 .^{10,11}$ Given the increased number of ED physicians, more facial lacerations might be repaired by ED physicians than before. In the present study's results, $71.7 \%$ of simple facial lacerations were repaired by an ED resident (Table 1). In the UK, $50 \%$ to $90 \%$ of simple facial lacerations are repaired by accident and ED doctors; the rest of them are referred to other specialists. $2,12,13$

Most patients may want to receive treatment for facial lacerations from a specialist such as a PS. A previous survey has shown that senior Accident and ED nurses preferred PSs for suturing their hypothetical facial lacerations. ${ }^{13}$ Following our hospital policy, we did not offer patients the option of the specialty from which they could receive surgical treatment. If we were to offer the option to choose the specialty, more patients would undoubtedly undergo surgical repair for their facial laceration by a PS. However, crowding in the ED has been recognized as a serious concern for EPs, especially in urban areas. Crowding is associated with unfavorable outcomes, such as longer times to treatment for patients with time-sensitive conditions and a greater degree of patient dissatisfaction. ${ }^{14,15}$ Table 1 shows that the length of stay for patients with PS repair was 2 times longer than with EP repair. If facial lacerations were referred freely to specialists, the increased length of stay of patients in the emergency room would make ED crowding worse.

As shown in Table 1, female patients showed a greater preference for PSs than male patients, as we expected. The caregivers of young patients ( 0 to 9 years) also preferred PSs. The degree of satisfaction was greater in female patients who underwent repair by a PS than by an EP. In young patients from 0 to 9 years of age, the degree of satisfaction was greater in patients repaired by a PS than in patients repaired by an EP. However, there is a limitation associated with these findings. The quality of surgical repair for a simple laceration is determined by the quality of training and by individual skill, not by affiliated specialty alone. Patients were cognizant of which specialty provided surgical treatment and were not blinded. The awareness that they received surgical treatment from a PS may have introduced bias. In any case, the overall satisfaction according to the specialty (EP vs. PS) did not differ for the entire survey sample.

A survey study reported that the single most important aspect of wound care is the cosmetic outcome in facial lacerations, while normal functioning is most important for other lacerations. Only $8 \%$ of survey participants responded that length of stay is the single most important aspect of wound care. ${ }^{4}$ However, the EP has the responsibility not only for treating emergency patients, but also for efficient ED operation. The decision to refer a patient to a specialist for facial laceration repair should weigh patient satisfaction against ED crowding.

There is another limitation in this study. The variance for satisfaction was evaluated by patients or guardians subjectively. As a result, scarring and suturing skills were not objectively considered in the analysis. The data in this study were limited to a single center, and the policies for facial lacerations are not the same at every hospital, which might limit generalization of our results.

In summary, female and young patients who underwent repair by PS were more satisfied than those treated by EPs. The overall satisfaction in the entire study population did not differ according to the department.

\section{CONFLICT OF INTEREST}

No potential conflict of interest relevant to this article was reported.

\section{REFERENCES}

1. Hutchison IL, Magennis P, Shepherd JP, Brown AE. The BAOMS 
United Kingdom survey of facial injuries part 1: aetiology and the association with alcohol consumption. British Association of Oral and Maxillofacial Surgeons. Br J Oral Maxillofac Surg 1998;36:3-13.

2. Ong TK, Dudley M. Craniofacial trauma presenting at an adult accident and emergency department with an emphasis on soft tissue injuries. Injury 1999;30:357-63.

3. Singer $\mathrm{A}$, Hollander JE, Quinn JV. Evaluation and management of traumatic lacerations. N Engl J Med 1997;337:1142-8.

4. Singer AJ, Mach C, Thode HC Jr, Hemachandra S, Shofer FS, Hollander JE. Patient priorities with traumatic lacerations. Am J Emerg Med 2000;18:683-6.

5. Sun BC, Adams J, Orav EJ, Rucker DW, Brennan TA, Burstin HR. Determinants of patient satisfaction and willingness to return with emergency care. Ann Emerg Med 2000;35:426-34.

6. Kwon SH. Survey analysis: utilizing SAS and SPSS. 1st ed. Paju: Jayu Academy; 2004.

7. Markovchick V. Suture materials and mechanical after care. Emerg Med Clin North Am 1992;10:673-89.

8. Tebble NJ, Adams R, Thomas DW, Price P. Anxiety and selfconsciousness in patients with facial lacerations one week and six months later. Br J Oral Maxillofac Surg 2006;44:520-5.

9. Kim YW, An SH, Ryu SY, Kim HY, Jeon BM, Kim KT. Clinical evaluation of facial laceration patients who visited tertiary emergency medical center. J Korean Soc Emerg Med 2001;12: 143-51.

10. Je SM, Choi YH, Park YS, Cho YS, Kim SH. How many emergency physicians does Korea need? J Korean Soc Emerg Med 2005;16:613-9.

11. Jung $\mathrm{CH}$, Lee $\mathrm{HM}$, Cho $\mathrm{KH}$. How many emergency physicians are needed in Korea? J Korean Soc Emerg Med 2013;24:331-7.

12. Allonby-Neve $C L$, Okereke CD. Current management of facial wounds in UK accident and emergency departments. Ann $\mathrm{R}$ Coll Surg Engl 2006;88:144-50.

13. Omovie EE, Shepherd JP. Assessment of repair of facial lacerations. Br J Oral Maxillofac Surg 1997;35:237-40.

14. Bernstein SL, Aronsky D, Duseja R, et al. The effect of emergency department crowding on clinically oriented outcomes. Acad Emerg Med 2009;16:1-10.

15. Key SJ, Thomas DW, Shepherd JP. The management of soft tissue facial wounds. Br J Oral Maxillofac Surg 1995;33:76-85. 